\title{
Postcardiotomy extracorporeal membrane oxygenation for refractory cardiogenic shock
}

\author{
Nilgun Bozbuga, MD, PhD
}

\author{
From the Department of Cardiovascular Surgery Istanbul University, Istanbul Faculty of Medicine, Istanbul, \\ Turkey. \\ Disclosures: Author has nothing to disclose with regard to commercial support \\ Received for publication June 7, 2018; revisions received June 7, 2018; accepted for publication June 7, 2018; \\ available ahead of print July 20, 2018 \\ Address for reprints: Nilgun Bozbuga, MD, PhD, Istanbul University, Istanbul Faculty of Medicine, Millet Cad- \\ desi, Çapa, 34116 Istanbul, Turkey (E-mail: nilgun.bozbuga@istanbul.edu.tr). \\ J Thorac Cardiovasc Surg 2018;156:1903-4 \\ $0022-5223 / \$ 36.00$ \\ Copyright (c) 2018 by The American Association for Thoracic Surgery \\ https://doi.org/10.1016/j.jtcvs.2018.06.030
}

Postcardiotomy cardiogenic shock (PCS) is a rare but catastrophic syndrome. Adult refractory PCS is different from pediatric PCS in terms of impaired right ventricular function. The incidence of refractory PCS in adult cardiac surgical patients ranges from $0.5 \%$ to $1.5 \% .^{1-3}$ When PCS is unresponsive to pharmacologic treatment with high dosages of inotropic drugs and intra-aortic balloon pump (IABP) support, venoarterial extracorporeal membrane oxygenation (VAECMO) is a salvage therapy that allows rapid restoration of circulation and active resuscitation.

VA-ECMO support is effective for the treatment of refractory PCS; however, the in-hospital mortality rate is high, and successful weaning has become a significant concern for critically ill patients. In a multivariable analysis published in this issue of the Journal, Fux and colleagues ${ }^{1}$ found arterial lactate level and ischemic heart disease to be independent predictors of 90-day mortality.

Lactate is a marker of tissue perfusion and a metabolic end product of anaerobic glycolysis that is produced by the reduction of pyruvate and primarily removed by the liver. Hyperlactatemia is related to inadequate cellular oxygen use and the development of an anaerobic metabolism. The normal plasma lactate concentration is 0.5 to $1.5 \mathrm{mmol} / \mathrm{L}$. No clear consensus has been reached as to the cutoff value for determining severe hyperlactatemia. Evidence has been found, however, that at lactate levels greater than $10 \mathrm{mEq} / \mathrm{L}$, the liver and kidney become saturated for lactic acid uptake of 2 to $5 \mathrm{mmol} / \mathrm{L} .4$

The level and dynamic behavior of lactate influenced by macrocirculation and microcirculation are good predictors for monitoring tissue oxygenation and guiding hemodynamic resuscitation. The use of an inotropic agent increases lactate production, and the transition from pulsatile to nonpulsatile blood flow to the main organs influences lactate clearance after cardiopulmonary bypass. Persistent anaerobic metabolism after VA-ECMO support, as measured by persistent high lactate values, is a strong predictor for mortality. Still needed is the

\section{References}

\begin{tabular}{l}
\hline VA-ECMO support for refractory PCS \\
Venoarterial ECMO support for refractory postcardiot- \\
omy cardiogenic shock. \\
Central Message \\
VA-ECMO support is effective for the treat- \\
ment of refractory PCS. Lactate behavior, espe- \\
cially clearance after the initiation of ECMO, \\
can predict in-hospital mortality in critically \\
ill patients.
\end{tabular}

See Article page 1894.

identification of risk factors, such as timing of initiation, type of cannulation, distal extremity hypoperfusion, and compartment syndrome.

Numerous preoperative and operative factors have been analyzed, and several independent risk factors for in-hospital mortality have been identified. ${ }^{3}$ In the analysis of Fux and colleagues, ${ }^{1}$ presence ischemic heart disease was found to be the only organ-specific pre-VA-ECMO risk factor for 90-day mortality. IABP is used in most VA-ECMO setups, with the aim of reducing the afterload to improve coronary perfusion and maintain pulsatile blood flow. Whereas VA-ECMO supports both the right and left ventricles and partially substitutes for lung function, IABP reduces the afterload to improve coronary perfusion and maintain pulsatile blood flow. The pulsatility effect of IABP support contributes to autoregulation recovery depending on the antegrade blood flow by spontaneous cardiac function.

Despite the beneficial effects of IABP on cardiac performance, the effects of end-organ blood flow are conflicting. The effect of IABP on the peripheral organ flow may be different for severe cardiac failure and spontaneous cardiac function during VA-ECMO. ${ }^{5}$ Rapid deflation of the IABP may obstruct peripheral VA-ECMO flow from the descending aorta to the ascending aorta in patients during myocardial stunning.

1. Fux T, Holm M, Corbascio M, Lund LH, van der Linden J. Venoarterial extracorporeal membrane oxygenation for postcardiotomy shock: risk factors for mortality. J Thorac Cardiovasc Surg. 2018;156:1894-902.

2. Rastan AJ, Dege A, Mohr M, Doll N, Falk V, Walther T, et al. Early and late outcomes of 517 consecutive adult patients treated with extracorporeal membrane oxygenation for refractory postcardiotomy cardiogenic shock. J Thorac Cardiovasc Surg. 2010;139:302-11.e1.

3. Biancari F, Perrotti A, Dalén M, Guerrieri M, Fiore A, Reichart D, et al Meta-analysis of the outcome after postcardiotomy venoarterial extracorporeal 
membrane oxygenation in adult patients. J Cardiothorac Vasc Anesth. 2018;32: 1175-82.

4. Renew JS, Barbara DW, Hyder JA, Dearani JA, Rivera M, Pulido JN. Frequency and outcomes of severe hyperlactatemia after elective cardiac surgery. J Thorac Cardiovasc Surg. 2016;151:825-30.
5. Aso S, Matsui H, Fushimi K, Yasunaga H. The effect of intraaortic balloon pumping under venoarterial extracorporeal membrane oxygenation on mortality of cardiogenic patients: an analysis using a nationwide inpatient database. Crit Care Med. 2016;44:1974-9. 